Article

\title{
Using Campaign Communications to Analyze Civility in Ranked Choice Voting Elections
}

\author{
Martha Kropf \\ Department of Political Science and Public Administration, University of North Carolina - Charlotte, Charlotte, NC 28223, \\ USA; E-Mail: mekropf@uncc.edu
}

Submitted: 22 March 2021 | Accepted: 14 May 2021 | Published: in press

\begin{abstract}
Theory suggests that ranked choice voting (RCV) may create a more civil campaign environment. As voters must rank candidates, the candidates have an incentive to work with each other more collaboratively. This study uses text analysis software (LIWC) to examine candidate tweets and newspaper articles in RCV versus specifically-chosen plurality cities for evidence of positivity or negativity. In quantitatively comparing the tweets, the results are mixed among the cities. Qualitatively, candidates seem to be more likely to engage each other in RCV cities than in plurality cities. Using LIWC to analyze newspaper articles for campaign tone, one can see that RCV city articles have significantly more positive than negative words. This is the first published study to use direct campaign communication data to study RCV elections and campaign civility. This research validates survey research indicating that citizens perceive RCV campaigns are more civil.
\end{abstract}

\section{Keywords}

civility; content analysis; Linguistic Inquiry and Word Count; ranked choice voting; sentiment analysis; text analysis; Twitter

\section{Issue}

This article is part of the issue "The Politics, Promise and Peril of Ranked Choice Voting" edited by Caroline Tolbert (University of lowa, USA).

(C) 2021 by the author; licensee Cogitatio (Lisbon, Portugal). This article is licensed under a Creative Commons Attribution 4.0 International License (CC BY).

\section{Introduction}

For decades, scholars have decried the level of negativity in American politics (e.g., West, 2014). Scholars and good government groups have suggested that election system change has the potential to ease conflict and negativity (e.g., Horowitz, 1991; Reilly, 2002). One change that is discussed is adopting 'ranked choice voting' (RCV). RCV allows voters to rank their preferences for candidates in a contest on one ballot. If no candidate wins a majority of votes, then the candidate(s) with the lowest number of top votes is eliminated and those voters' second choice votes allocated among the remaining candidates. The process continues until there is a majority winner.

Why would RCV result in campaigns that are more civil? (That is, less negative and more positive?) Under an RCV system, there is an incentive for more positive campaigning since each ballot is not an 'all or nothing' battle, as in plurality systems. A candidate has much less incentive to 'go negative' for fear of offending a voter who might have given them a second-place vote (Donovan, Tolbert, \& Gracey, 2016). The possibility of the second-place vote is also a reason for candidates to work together (Robb, 2011). Similarly, RCV also promotes more bargaining and accommodation across different groups (Reilly, 2002). Examining five country case studies, Reilly (2002) finds that candidates of differing ethnicities "reach out to ethnic groups other than their own" (p. 159) and moderate their positions on divisive issues. The logical result should be a more positive than negative campaign, characterized by bargaining and accommodation.

Other empirical research bears out this proposition. Donovan et al. (2016) conduct surveys among citizens in matched cities in the United States with and without RCV. They find that voters were less likely to perceive negativity and criticism in the local campaigns in RCV cities. Citizens also reported that they were more satisfied 
with campaign conduct in RCV cities. Robb (2011) took a different approach, analyzing campaign mail in San Francisco local elections from 2002 when instant run-off voting (another name for RCV) began there, until 2008. Robb found that "a unique form of campaigning emerged in 2004 with Team ads. Team ads are candidates urging voters to choose them and rank others as well" (Robb, 2011, p. 110).

These advances in understanding the tone of the RCV campaigns are critically important to making policy decisions about the use of RCV over other electoral systems. Yet, survey research only reveals the perceptions of voters, and not what candidates are actually saying. Other than Robb's dissertation, there does not appear to be content-analytic work that measures whether RCV cities have more civil campaigns. In order to supplement prior work, this research analyzes a corpus of candidate tweets in three RCV cities and seven control cities-the same cities utilized by Donovan and colleagues (2016). While newspaper articles are not candidate communications, this research also analyzes newspaper content from the ten cities to explore the overall tone of the campaign, in order to validate the Twitter analysis.

To analyze tweets and newspaper articles, this work employs a text analysis software called Linguistic Inquiry and Word Count (LIWC) designed by Pennebaker and colleagues (Pennebaker, Chung, Ireland, Gonzales, \& Booth, 2007). The software searches for words that Pennebaker and colleagues have categorized (and validated) as words indicating positive and negative emotions, as well as cognitive process words indicative of compromise (Pennebaker et al., 2007). The results of the city comparisons presented here are mixed, but lean toward support for the idea that campaigns are more positive in RCV cities.

\section{Theory and Previous Literature}

A key question with which political scientists grapple is that of election system design's effect on democracy (Horowitz, 1991). Scholars who examine preferential voting systems such as RCV find that the systems where voters may rank alternatives create more satisfaction with democracy among citizens (e.g., Donovan, Tolbert, \& Gracey, 2019; Farrell \& McAllister, 2006; but see Nielson, 2017). Scholars of democracy also consider civility and civic discourse "a fundamental tenet of democracy" (Herbst, 2010, p. 126) and suggest that incivility "can be used to distract, demotivate, and distance average citizens from engaging in fruitful and productive political conversations" (Bratslavsky, Carpenter, \& Zompetti, 2020, p. 596). Accordingly, scholars have examined the effects of RCV on campaigns and the citizen-perceived tone of campaigns (Donovan et al., 2016; John \& Douglas, 2017). Discourse that one might reasonably call 'civic' in a democracy is, of course, characterized by less negativity and more positivity. However, Eulau (1973) argues a "politics of civility" also includes "a broad range of poten- tial behavioral patterns that can be expressed by such participles as persuading, soliciting, consulting, advising, bargaining, compromising, coalition-building, and so on" (p. 368).

Theoretical reasoning for why the tone of the discourse may be more civil in RCV elections versus plurality elections is that candidates are campaigning not just for a first-place vote, but also for second, and, potentially, third-place votes-or more (Donovan et al., 2016; John \& Douglas, 2017; Reilly, 2002). Candidates must appeal to, or at least not offend, those voters other than their core supporters. Thus, RCV reduces the incentive for negative campaigning and increases the incentive for positive campaigning as well as bargaining and cooperation among candidates. Reilly (2002) analyzes cases of societies divided by ethnic differences. He finds evidence that indicates RCV does create more bargaining and compromise among ethnic groups (Reilly, 2002).

Notably, Donovan and colleagues (2016) survey citizens in the 10 American cities considered in the present article. They controlled for various demographic and political factors, as well as how closely the citizens followed the campaigns and whether the candidate they supported won. Donovan and colleagues found:

Respondents living in cities using preferential voting were significantly more likely to express higher levels of satisfaction with the conduct of local campaigns, they were less likely to say that local candidates criticized each other frequently, and they perceived their local election campaigns as less negative. (Donovan et al., 2016, p. 160)

However, they write that "the proposed causal mechanism here is the manner in which the electoral systems affect how candidates campaign" (Donovan et al., 2016, p. 159). They note, "they are not in a position to directly observe how the candidates conducted their campaigns" (p. 159). These results are still striking, yet some investigation as to the causal mechanism would increase confidence in already strong findings.

In contrast, Robb (2011) directly observed campaign mail. Robb content analyzed mass mailers distributed by candidates in the races using instant run-off voting. She supplemented her work with interviews with candidates, campaign consultants, and party officials. Mailers and phrases within them were classified for negativity and cooperation. Robb found that candidates utilized team ads (Robb, 2011). Team ads led to coordinated attacks, though the coordinated attacks were very limited. Robb's analysis indicated that campaigning was much less negative, and significantly more positive.

The present research fills a number of gaps aside from just being another test of the RCV civility theory. First, the work shows what the media environment is in the RCV and plurality cities beyond mailed advertisements. One should not automatically conclude that tweets or newspaper articles lead to opinion change, but 
for the purposes of causal mechanism in Donovan et al. (2016), there is a need to measure the tone separate from what voters perceive. Second, does RCV promote civility in campaigns beyond those in San Francisco? Beyond 'positivity' or 'negativity,' is there evidence of bargaining and compromise in the tone of the campaigns, in particular, in candidate tweets? Finally, while scholars have looked to newspaper content to measure campaign tone in communities (Peterson \& Djupe, 2005), no scholar has used Twitter to analyze campaign tone in the context of RCV and in local campaigns. Importantly, scholars such as Bratslavsky and colleagues (2020) call Twitter a part of an 'infrastructure of incivility' in examining Donald Trump's tweets. A bit older data (from 2013, as in this work) should minimize or remove the idea that candidates are only imitating Trump.

Obviously, Twitter has not been around as long as newspapers. Thus, scholars have been more likely to analyze newspaper coverage to measure the overall tone of campaigns, rather than tweets (e.g., Peterson \& Djupe, 2005; Ridout \& Franz, 2008). While civil campaigns may be a 'tenet of democracy,' scholars have long examined the effects of negative campaigns on political behavior and there is mixed evidence. Scholars such as Sigelman and Kugler (2003) analyzed newspaper content, calling it a 'social science-style' measure of campaign tone. Also, Ridout and Franz (2008) compared various methods of evaluating campaign tone and found newspaper content, political advertising, and citizen perceptions were all correlated, and substituting them for each other does not lead to differing conclusions about political behavior. Newspaper coverage then, provides a method to validate the Twitter methodology.

\section{Analyzing Discourse}

In order to analyze discourse, this article utilizes 'sentiment analysis.' 'Sentiment' is often considered to be conceptually different from public opinion. Pang and Lee (2008) argue that 'sentiment analysis' is "computational treatment of opinion, sentiment, and subjectivity in text" (p. 6). One computation method which was developed more than 30 years ago appears to be validated (using expert panels) and used in a variety of contexts. The LIWC software was developed by Pennebaker and colleagues (e.g., Pennebaker et al., 2007). The software uses a 'bag of words' approach - with a dictionary of words denoting certain emotions and cognitive processes. Pennebaker and colleagues note that "LIWC uses a word count strategy whereby it searches for over 2,300 words or word stems within any given text file. The search words have previously been categorized by independent judges into over 70 linguistic dimensions" (Pennebaker, Mehl, \& Niederhoffer, 2003, p. 553).

LIWC analyzes the words chosen by individuals (or located in the text) rather than the integrative complexity of phrases and sentences, with the idea that "seemingly insignificant words that people use are particularly telling about their emotions, motives, and life circumstances" (Pennebaker \& Lay, 2002, p. 273). For example, use of the word 'we' can indicate a sense of community, or a person in a close relationship. Table 1 indicates the 'emotions/sentiments' and 'cognitive processes' relevant to the RCV civility theory that are measured by the LIWC program, as well as examples of each.

Not only did/do Pennebaker and their teams validate the dictionaries, but so have other researchers. Young and Soroka (2012) created the Lexicoder Sentiment Dictionary (LSD), which they find is most closely related to human coding of the affective tone of New York Times articles compared to other dictionaries. However, Young and Soroka find that their dictionary (LSD), human coders, and LIWC correlate highly in coding positive and negative. "[LIWC] is one of the few to contain large positive and negative valence categories; it is also one of the only dictionaries making liberal use of truncation" (Young \& Soroka, 2012, p. 218). They find that when a dictionary uses truncation (e.g., 'agreeab*' or 'battle*'), it improves the performance of the dictionary (see Table 1 for examples). Young and Soroka also provide evidence that indicates that LSD's dictionary is the state of the art when it comes to measuring positive and negative tone.

A difference between the LSD and LIWC is that LIWC analyzes not only whether the text contains positive and negative words, but also other emotion words (anger, anxiety). It also includes words that are indicative of cognitive process: social words, exclusiveness, inclusiveness, tentativeness and certainty (see Table 1). If the theory of RCV civility holds, when examining the body of tweets and newspaper content, one should observe more positive words and fewer negative words in RCV cities, and fewer anxiety and anger words. One should also observe cognitive process words denoting bargaining and compromise (more inclusiveness and less exclusiveness; more tentativeness and less uncertainty). In terms of 'reaching out,' there should be more social words in RCV than plurality communities. The way that these concepts are measured, however, does not exclude a result that the campaign tone is, for example, both more inclusive and more exclusive. While subtracting the results for the opposite concepts ('positive-negative' or 'inclusiveexclusive') would eliminate that possibility, the measure would mask a city that was simultaneously very positive and very negative.

Since it is analyzing word use, LIWC will capture the idea that political actors may engage in a complex mix of negative and positive over the course of a campaign. The software is designed to analyze individual-level differences in affect, but one can measure the discourse over the campaign as well. By combining tweets from all the candidates, one can measure the percentage of the words that are positive and those that are negative. One can do the same with each piece of newspaper content. For each affect and each cognitive process, LIWC outputs the percentage of words in the text that are coded in the dictionary as measuring the given concept. 
Table 1. Conceptualizing and operationalizing 'civility.'

\begin{tabular}{lll}
\hline Emotion (Affect) Coding & $\begin{array}{l}\text { Why Does Existence Measure Civil/Cooperative } \\
\text { or Negative? } \\
\text { (Conceptualization) }\end{array}$ & $\begin{array}{l}\text { How Does LIWC Operationalize the } \\
\text { Sentiment? }\end{array}$ \\
\hline Positive Emotions & $\begin{array}{l}\text { Examining whether or not the campaign is } \\
\text { positive or negative, the use of 'positive' } \\
\text { emotion terms is one important indicator. }\end{array}$ & $\begin{array}{l}\text { Terms such as 'agreeab*,' 'freed,' } \\
\text { 'bless' and 'grin' }\end{array}$
\end{tabular}

Negative Emotions Examining whether or not the campaign is positive or negative, the use of 'negative'

Terms such as 'maddening,' 'alone,' 'battl*' emotion terms is one important indicator.

Anger

Anxiety

Inclusive

Exclusive

Tentativeness

Certainty

Social
According to the American Psychological Association (n.d.-a), 'anger' is "an emotion characterized by antagonism toward someone or something you feel has deliberately done you wrong." Young and Soroka (2012) combine 'anger' with 'negative.'

According to the American Psychological Association (n.d.-b), "anxiety is an emotion characterized by feelings of tension, worried thoughts and physical changed like increased blood pressure." Young and Soroka (2012 combines 'anxiety' with 'negative.'

Cognitive Process Words

These words suggest that individuals are interacting - talking and sharing, suggesting cooperation.

If the campaign is civil, one should expect them to use more 'inclusive' words.

If the campaign is civil, one might expect them to use more 'exclusive' words.

Tentativeness may indicate a willingness to compromise and bargain.

Certainty may indicate less willingness to compromise and bargain.
Terms such as 'assault,' 'mad,' 'cheat*,' etc.

Terms such as 'craz*,' 'dread,' 'feared,' etc.

Terms such as 'amigo,' meeting, they, themselves, emails, etc.

Terms such as 'add,' 'open,' 'we,' 'with,' etc.

Terms such as 'rather,' 'versus,' 'exclu*'

Terms such as 'approximat*,' 'fuzz*,' 'dunno,' etc.

Terms such as 'blatant*,' 'clear,' 'facts,' etc.

Note: * The stars in the table indicate that the words are stems and the program will search for the stems with differing suffixes. Source: Operationalizations from Pennebaker et al. (2007).

\section{What Cities Are Analyzed?}

This work is based on local mayor and city council elections held in Fall 2013. There are differences in electoral systems across cities, allowing one to take advantage of the natural variation to examine how plurality and RCV cities differ in campaign tone. Three cities utilizing RCV voting are matched with seven cities using plurality voting. In selecting cities, those with similar time frames for electing the same type of offices, and other electoral features are necessary (off-year election, open seats, competitive; see Table 2). Other considerations are city size, region, how the cities' citizens voted, and the racial composition of the voting age population. Each RCV city is matched with multiple plurality cities (see Table 2). The research design should minimize differences (other than electoral rules) and allow the scholar to analyze the differences in campaign content (see Table A-1 in the Supplementary File for information comparing the cities). This analysis is bivariate. As such, causal inference is limited even if the cities are perfectly matched. The lack of random sampling also limits causal inference. These cities are selected in order to complement the work of Donovan and colleagues (2016). Table 2 lists the selected 
Table 2. Cities and elections for content analysis.

\begin{tabular}{ll}
\hline RCV Cities & Matched Plurality Cities \\
\hline Minneapolis, MN & Boston, MA; Tulsa, OK; Seattle, WA \\
St. Paul, MN & Cedar Rapids, IA; Des Moines, IA \\
Cambridge, MA & Lowell, MA; Worcester, MA \\
\hline
\end{tabular}

cities. Table 3 lists details about the contests, including the specific contests analyzed herein.

Not all candidates tweet, though most of the 'viable' candidates in large cities do (see Tables A-2-A-11 in the Supplementary File). As one moves to examining city council races (and district ones such as St. Paul, Des Moines, and Cedar Rapids), even fewer candidates tweet-in Des Moines and Cedar Rapids, for the first district council member races, there are no candidate Twitter accounts. There were some for the at-large races, but very few. Thus, for the comparison of tweet tone, this analysis looks to Spokane, Washington and Madison, Wisconsin. While these were not chosen as 'control cities' in Donovan et al. (2016), they are similar on the many factors affecting the selection (see Table A-1 in the Supplementary File). One exception is that the Madison election in question was held in April, not late Fall, 2013. It should not significantly affect the analysis, but the reader should keep it in mind.

Plurality elections often have primaries or preliminary elections, so time periods for the searches are slightly different among the different cities (see Table 4). For cities holding preliminary/primary elections, the search was two months before the initial election through November when the general election was held. For those cities having only November elections, the search was one month before the 'traditional' time frame of 'after Labor Day' to factor in the idea that campaigns are beginning more and more early. The search continued through the end of November in order to capture any candidate tweets that might reflect a 'sore loser effect.' If the RCV civility holds, one should expect it to continue to hold even after a candidate has lost.

\section{Twitter Analysis Methods}

In locating tweets to observe, one can argue it is most consistent with RCV civility theory to analyze the messages that candidates communicate. The probability of locating all the tweets issued by candidates is much higher than finding all tweets about the 'Tulsa election,' given that there could be a variety of hashtags. However, it is entirely possible that candidates use Twitter with the same pattern one might observe with negative campaign ads: A primary source of negativity is so-called 'outside money' or non-candidate funds (e.g., Magleby, Monson,

Table 3. Legal-institutional environment of each election analyzed.

\begin{tabular}{|c|c|c|c|}
\hline City & Type of Election & $\begin{array}{l}\text { Number of } \\
\text { Candidates for } \\
\text { First or Primary } \\
\text { Election }\end{array}$ & $\begin{array}{c}\text { Number of } \\
\text { Candidates for } \\
\text { General/ Run-Off } \\
\text { Election }\end{array}$ \\
\hline Minneapolis, MN & Mayor & NA & 35 \\
\hline Boston, MA & Mayor & 12 & 2 \\
\hline Tulsa, OK & Mayor & 3 & 2 \\
\hline Seattle, WA & Mayor & 9 & 2 \\
\hline St. Paul, MN & City Council Ward 1 & NA & 7 \\
\hline Cedar Rapids, IA & City Council Ward I (At-Large also available) & 7 & 4 \\
\hline Des Moines, IA & City Council Ward I (one At-Large seat also available) & $5 / 3$ & $2 / 2$ \\
\hline Cambridge, MA & City Council At-Large (nine seats available) & NA & 25 \\
\hline Lowell, MA & City Council At-Large (nine sets available) & 22 & 18 \\
\hline Worcester, MA & $\begin{array}{l}\text { City Council At-Large (six seats available; candidates } \\
\text { also run for mayor unless they specify they want to } \\
\text { be removed from the mayoral ballot; must win seat } \\
\text { on city council and mayor to be mayor) }\end{array}$ & NA & 12 \\
\hline \multicolumn{4}{|l|}{ Added Cities } \\
\hline Madison, WI & City Council District I & NA & 2 \\
\hline Spokane, WA & City Council Ward II & NA & 2 \\
\hline
\end{tabular}


Table 4. Time frame of election campaign in each city.

\begin{tabular}{lll}
\hline City & Date of First/Primary Election & Date of Second/Run-Off Election \\
\hline Minneapolis, MN & NA & November 5, 2013 \\
Boston, MA & September 24, 2011 & November 5, 2013 \\
Tulsa, OK & June 11, 2013 & November 12, 2013 \\
Seattle, WA & August 6, 2013 & November 5, 2013 \\
St. Paul, MN & NA & November 5, 2013 \\
Cedar Rapids, IA & November 5, 2013 & December 3, 2013 \\
Des Moines, IA & November 5, 2013 & December 3, 2013 \\
Cambridge, MA & NA & November 5, 2013 \\
Lowell, MA & September 24, 2013 & November 5, 2013 \\
Worcester, MA & No preliminary election held in 2013 & November 5, 2013 \\
Cities Added to the Analysis & (see Kotsopoulos, 2013) & \\
Madison, WI & & \\
Spokane, WA & NA & November 5, 2013 \\
\hline
\end{tabular}

\& Patterson, 2007). Perhaps there are non-candidate tweets that are far more negative about opponents than the candidate tweets (letting interest groups or others do the heavy lifting so voters will not attribute negativity to the candidate). Locating tweets for analysis by searching for candidate does not allow one to analyze what outside groups are communicating, but it does not miss what the candidates are tweeting. This is a potential weakness in the study design that should be minimized by doing the second portion of the analysis, examining newspaper content.

This research used Twitonomy.com-an analytics engine that connects to Twitter, and allows one to obtain all the tweets communicated by a given candidate in a given time frame. In order to provide a sense of how much the candidates tweet generally, this research also collected information on how much the candidates tweeted during the year (see Tables A2-A11 in the Supplementary File).

One must remember that tweets have unusual symbols that appear as words, but are not. This should not affect the overall results, but only the number of words used to calculate the percentage of words which fit each category. For example, RT=re-tweet where a person repeats/copies a message sent by another person. The @ symbol refers to a particular person's user name or 'handle' (e.g., @betsyhodges is Betsy Hodge's handle). Often tweets are followed by websites referring to an article, a picture or a video. Thus, the percentage of words may seem very small.

The files analyzed include all tweets and retweets. While it is possible the candidates did not author their own tweets, the tweets are tweeted in their names, and they are responsible for the words. Also, the goal of this work is not to analyze the personality of the candidates, but to understand the tone of the messages tweeted as a part of the campaign. Minimal text pre-processing is done herein, relying on stems with '*' to catch the key words. The number sign (\#) is a hashtag which indicates the subject of the tweet. Hashtags often have substantive meanings (e.g., \#mplsmayor-here the subject of the tweet is the mayor's contest in Minneapolis). In order to preserve reliability, this research does not assume what the candidates meant when they combined words in hashtags, so words in hashtags are not separated. For each type of contest and type of electoral system, individual tweets are not analyzed. Rather, the tweets are aggregated. Not only is each tweet too short to provide a reliable measurement, but also, the idea is to understand the overall tone of discourse, even if some candidates tweet more than others (individual candidate tweets are processed and results found in the Supplementary File, Tables A-12-A-19).

\section{Twitter Analysis Results}

\subsection{Quantitative Results}

First, the reader will see the results of examining the tweets from candidates in the cities where the mayoral election was the focus (Minneapolis, Boston, Tulsa, and Seattle). Table 5 compares the RCV and plurality cities in terms of percentage of the words tweeted that indicate the concept. Table 5 shows that words in campaign tweets indicate considerably more positivity than negativity for every city. Mayoral RCV tweets do not, on average, contain a higher percentage of positive words than plurality cities. The analysis also indicates more anger and anxiety in mayoral RCV cities, though the percentages are very low. In terms of the cognitive process words indicating bargaining and compromise, the results are quite mixed-mayoral RCV tweets indicate 
Table 5. Tweet word comparisons of RCV and plurality mayoral races.

\begin{tabular}{lccccc}
\hline Affective & Positive & Negative & Anger & Anxiety \\
\hline RCV & $4.75 \%$ & $0.80 \%$ & $0.26 \%$ & $0.10 \%$ \\
Plurality & $5.44 \%$ & $0.50 \%$ & $0.19 \%$ & $0.06 \%$ & \\
Cognitive Process & Tentative & Certainty & Social & Inclusive & Exclusive \\
\hline RCV & $1.14 \%$ & $1.06 \%$ & $7.50 \%$ & $2.84 \%$ & $1.24 \%$ \\
Plurality & $0.76 \%$ & $0.73 \%$ & $7.68 \%$ & $2.66 \%$ & $0.76 \%$ \\
\hline
\end{tabular}

Notes: Categories are percent of total words across all candidate tweets; statistical significance is not computed because the percentages represent the corpus of tweets.

more tentative words and more certain words. Mayoral $\mathrm{RCV}$ tweets have, on average, more inclusive and more exclusive words and fewer social words. These results provide little support for the hypotheses and the theory of RCV civility.

Table 6 presents the results of the city council tweets analysis. Plurality city tweets have more positive words and fewer negative words. RCV city council tweet words are more tentative but also more certain; more inclusive but also more exclusive. Finally, candidates use more social words in plurality cities. Again, this is not strong evidence to support the RCV civility hypothesis.

\subsection{Tweet Examples}

The mixed findings for the quantitative analysis might be an artifact of measurement, or perhaps occur because tweets have differing uses. Tweets are often used to announce events, thank supporters, and even thank those who hold candidate forums - and it is highly likely that both RCV and plurality candidates do those sorts of things. A more qualitative approach, that is, reading the tweets, may provide additional insights. Perhaps, as with campaign mailers (Robb, 2011), there could be teamwork among candidates or other activities.

In Minneapolis (RCV), many of the candidates referenced each other. An especially popular tweet and re-tweet (RT) was the report of someone's votes for the tweeting candidate and other candidates as well (so for example, a person would report they were voting for Hodges and two others, and Hodges would retweet it). In the tweets, one candidate might thank a debate-sponsoring organization, but also reference several other candidate handles in the tweet. Betsy Hodges even tweeted that she liked "Winton's comments on pedestrian improvements." Cam Winton reported that he would vote for himself and others. Tweets also encouraged the voters to come to an event or to make a certain candidate their first choice. Note the examples in Box 1; it is not that negative tweets do not exist. Rather, the examples appear rather subtle as in the Cherryhomes tweet referring to a 'spat' during one of the debates between Winton and Andrews.

In Boston, a plurality city, when the candidates mentioned each other, there was negativity and attacking, but many positive tweets about upcoming events. Marty Walsh only briefly mentioned John R. Connolly (see Box 1). The same appeared to be the case in Tulsa between the two finalists. In Seattle, in examining the two finalists, Michael McGinn never mentioned Ed Murray in his tweets. Most of the tweets regarded issues and events in Seattle. The failure to engage the other candidate-in either a negative or a positive tone is especially notable. It could indicate: 1) There was little to no bargaining or accommodation, and/or 2) Perhaps the candidates asked some other group to do "heavy lifting' where negativity was concerned or an interested party/interest group did the heavy lifting without the candidate asking. In Tulsa, there were three handles for Dewey Bartlett. One was so negative, that the research assumed it was not Bartlett. For example, a tweet after the election read: “@MayorTaylor that was such an asswhipping.... does it still sting a little?"

Table 6. Tweet word comparisons of RCV and plurality city council races.

\begin{tabular}{lccccc}
\hline Affective & Positive & Negative & Anger & \multicolumn{2}{c}{ Anxiety } \\
\hline RCV & $4.76 \%$ & $0.74 \%$ & $0.24 \%$ & $0.10 \%$ \\
Plurality & $5.29 \%$ & $0.63 \%$ & $0.18 \%$ & $0.06 \%$ & \\
& & & & & Exclusive \\
Cognitive & Tentative & Certainty & Social & Inclusive & $1.15 \%$ \\
\hline RCV & $1.10 \%$ & $0.99 \%$ & $7.46 \%$ & $2.84 \%$ & $0.77 \%$ \\
Plurality & $0.76 \%$ & $0.74 \%$ & $7.59 \%$ & $2.64 \%$ & \\
\hline
\end{tabular}

Notes: Categories are percent of total words across all candidate tweets; statistical significance is not computed because the percentages represent the corpus of tweets. 
Box 1. Tweet examples from RCV mayor's race and plurality mayor's races.

\section{RCV (Minneapolis)}

\section{Hodges Tweets}

Minneapolis! Come join Betsy, her supporters and her staff for an event at @612Brew at 4:00PM today 2 watch the election results! \#mplsmayor

RT @wr3n: Good luck to my 3 picks 4 \#mplsmayor. @betsyhodges @swoodruffmpls @Don_Samuels

RT @MackenzieNEmpls: Very happy for a transportation equity question. Liking Winton's comments on pedestrian improvements. \#transportationf...

\section{Andrews Tweets}

@MayoralForum @5hauser Thank*you*_good to talkw/u all @CherryhomesMpls, @betsyhodges, @Don_Samuels \&amp; @cam_winton \#mplsmayor

Make calls for Mark! Everybody's doing it--everybody! \#mplsmayor http://t.co/rKtrTEM2vg

http://t.co/grCzoJiUcV

\section{Cherryhomes Tweets}

RT @wccoradio: Hodges on who she would vote for: Cherryhomes and Cohen. \#wccodebate

RT @StribRoper: \#mplsmayor candidates discussed security in public housing yesterday. See their answers + a brief Andrew/Winton spat: http:...

RT @Mrao_Strib: In first 5m of debate, @cam_winton praises @betsyhodges' integrity,

\section{Winton Tweet}

RT @r_delong612: Excited to vote for @betsyhodges, @don_samuels, @cam_winton for \#mplsmayor! \#nomoreflyers

\section{Boston}

\section{Walsh Tweets}

Fact check: John Connolly admitted to sending anonymous negative mailers in his City Council race. http://t.co/LxgOTNA5nz \#bosmayor

Fact check: John Connolly's campaign is spending thousands on push polls to attack Marty Walsh. http://t.co/TIDxJ9cr48 \#bosmayor

Earlier today, I responded to the negative attacks by the Connolly campaign http://t.co/d0Zklx3NaZ \#bosmayor

\section{Connolly Tweets}

I'm asking @Marty_Walsh to join me in keeping outside special interest money out of the Final Election.

RT @paul_mcmorrow: \#bosmayor started today just shy of $\$ 3 \mathrm{M}$ in outside union and super PAC money, now we're over $\$ 3.1 \mathrm{M}$. $78 \% / 18 \%$ pro Walsh/...

\section{Seattle}

\section{Murray Tweets}

@KIRO7Seattle reports on the McGinn's campaign's outrageous cyberbullying of a Planned Parenthood staffer. Please join us at tomorrow's pride picnic! It'll be a good time with great people! https://t.co/KtFI4oRzYH

\section{McGinn Tweets}

No specific Walsh mentions

Come on down to the 2nd annual polish fest for pierogies, kielbasa \& more! @PFSeattle @seattlecenter http://t.co/uuuliwlb1i 
Box 1. (Cont.) Tweet examples from RCV mayor's race and plurality mayor's races.

Tulsa

\section{Bartlett Tweets}

A vote for Taylor is a vote for Bloomberg. Their liberal policies and values mirror each other. RT \&amp; share! http://t.co/iUFNe

TRICK or TREAT: @MayorTaylor has given thousands to @BarackObama. Spooky how liberal she is!

\section{Taylor Tweets}

Retweet if you're worried about crime ("Fortunately, we are addressing crime very, very well," Bartlett said) http://t.co/bjqEoFVo8H

Police slam Bartlett, says talk of layoffs hurts public safety \#TulsaCrime \#Tulsa http://t.co/oboRjak0ev

\section{Newspaper Article Analysis Methods}

Newspaper articles are considered because every city considered in this analysis has a local newspaper which covers the local elections. If there was more than one newspaper, the one with the largest circulation was chosen. Content of newspapers includes the articles, but also letters to the editor, on-line reporter blogs, and candidate Question \& Answer articles-herein, for convenience, they are all referred to as 'articles' or 'content.' There may be those who argue that letters to the editor should not be included because those who write letters have stronger feelings than the typical citizen. They are included because they are a part of the overall tone of the discourse. Perhaps, those who write them are the most likely to be paying attention to the campaigns.

Every 'article' is a unit of analysis and is analyzed using the LIWC text analysis program. Unlike tweets, individual articles are long enough to provide a more reliable analysis, so the articles are not aggregated (articles averaged 595.5 words). In order to locate the articles, I used the Newsbank database, which provides complete, fulltext newspaper content both on-line and in print from local sources. There were occasionally repeated articles (on-line and print versions), so the research eliminates the on-line version of the article. In locating newspaper articles, Newsbank did not contain The Des Moines Register, which was accessed via Proquest. Table 7 lists the newspapers, the time periods, and the search terms used to locate content.

\section{Newspaper Article Analysis Results}

This section first presents some overall information on the percentage of positive and negative words. Then it proceeds to quantitative comparisons of the RCV and plurality mayor and city council elections on both the affective sentiment words and the cognitive process words. A brief qualitative analysis will follow. The quantitative newspaper analysis is more supportive of the RCV civility theory.

Overall, using the LIWC analysis and subtracting negative percentage of negative words from positive percentage of words, close to 89 percent of RCV city newspaper articles have a greater number of positive words than negative ones, and about 80 percent of plurality cities'

Table 7. Newspaper content analysis parameters.

\begin{tabular}{llll}
\hline City & Time Frame & Newspaper & Search Terms \\
\hline Minneapolis, MN & August 1, 2013-November 30, 2013 & Minneapolis Star-Tribune & Minneapolis Mayor Election \\
Boston, MA & July 1, 2013-November 30, 2013 & Boston Globe & Mayor, Election \\
Tulsa, OK & April 1, 2013-November 30, 2013 & Tulsa Journal-World & Mayor, Election \\
Seattle, WA & June 1, 2013-November 30, 2013 & Seattle Times & Mayor, Election \\
St. Paul, MN & August 1, 2013-November 30, 2013 & Minneapolis Star-Tribune & St. Paul City Council, Election \\
Cedar Rapids, IA & August 1, 2013-December 30, 2013 & The Gazette & City Council, Election \\
Des Moines, IA & August 1, 2013-November 30, 2013 & Des Moines Register & City Council, Election \\
Cambridge, MA & July 1, 2013-November 30, 2013 & Cambridge Chronicle & City Council, Election \\
Lowell, MA & July 1, 2013-November 30, 2013 & Lowell Sun & City Council, Election \\
Worcester, MA & August 1, 2013-November 30, 2013 & Worcester Telegram and & City Council, Election \\
\end{tabular}


content has more positive than negative. Conversely, 12 percent of RCV city articles have more negative than positive words where close to 20 percent of plurality city articles are more negative than positive (a statistically significant difference).

\subsection{Quantitative Results}

Table 8 analyzes the measures of affect and cognitive process predicted by the RCV civility theory. Table 8 demonstrates that articles in RCV cities use significantly more positive words and significantly fewer negative words, which supports the hypotheses predicted by the theory of RCV civility. Considering language of compromise, Table 8 demonstrates that RCV-city articles show both significantly more tentativeness in words and significantly more certainty in words. As with the Twitter results, the analysis indicates simultaneously more compromise and less compromise. RCV city articles show more inclusive words than plurality cities do, but the difference is not statistically significant. Exclusive word use is not different between the types of cities. Also, while more social words are used in RCV cities than the plurality cities, that difference does not achieve statistical significance (see Table A-21 in the Supplementary File for a breakdown of the cities in terms of percentage of positive and negative words).

\subsection{Newspaper Qualitative Examples}

This section provides examples of newspaper content focusing on the most positive and most negative articles in the mayoral contests as indicated by the LIWC analysis. One can see that many of the most negative are from opinion pieces-either letters to the editor, unsigned editorials or opinion columns written by public citizens rather than staff writers. There is no evidence either way about whether these letters and other opinion pieces were driven by the candidates, and among these articles, no qualitative evidence that there are differences between RCV and plurality cities-both are negative and positive. While Twitter content showed evidence of bargaining and accommodation, the newspaper articles did not indicate any of these themes or differences among cities.

The most positive Minnesota (RCV) article was published the day after the election; an unsigned editorial praising the choice of the electorate: "Hodges, 44, offered youthful vigor, gender diversity (she will be the city's second female mayor), fiscal discipline, and new approaches to improving schools and transit" ("Youth, diversity," 2013). The fact that the most positive article was written after Election Day is consistent with the measurement strategy of this work examining tone through the end of November.

In contrast, the most positive from Seattle (plurality) is actually a bit negative, but it would be overspeaking the evidence to say that it represents support for the idea that RCV campaigns are more civil than plurality ones. It came from a column published on September 3, 2013:

It's an election year, so it's easy to be a little cynical about any gathering with an open mike and a politician looking over his notes. But it was impossible to feel jaded about the 2013 Mayor's Arts Awards, held under a glorious blue sky at Seattle Center on the eve of Bumbershoot. The event was a welcome reminder that Seattle is filled with good people doing good work-despite all the yammering and slamming that goes on around here. (Brodeur, 2013)

A letter to the editor proved to be the most negative article in Minneapolis (RCV) over the course of the election season. The writer argued with the Star Tribune's endorsement of Betsy Hodges:

Wherever it has been tried, the Democrats' expansion of the numbers of citizens dependent on

Table 8. Comparison of articles from RCV cities and plurality cities.

\begin{tabular}{|c|c|c|}
\hline & RCV City Articles ( $n=146$ ) & Plurality City Articles $(n=848)$ \\
\hline \multicolumn{3}{|l|}{ Affective Content } \\
\hline Positivity & $2.72 \% * *$ & $2.49 \%$ \\
\hline Negativity & $1.08 \% * * *$ & $1.37 \%$ \\
\hline Anger & $0.26 \% *$ & $0.31 \%$ \\
\hline Anxiety & $0.12 \%$ & $0.12 \%$ \\
\hline \multicolumn{3}{|c|}{ Cognitive Process Content } \\
\hline Tentativeness & $1.71 \% * *$ & $1.50 \%$ \\
\hline Certainty & $1.11 \% * *$ & $0.98 \%$ \\
\hline Social & $8.72 \%$ & $8.40 \%$ \\
\hline Inclusive & $3.94 \%$ & $3.82 \%$ \\
\hline Exclusive & $1.40 \%$ & $1.41 \%$ \\
\hline
\end{tabular}

Notes: Difference of Means test conducted with a two-tailed test of significance; numbers in table are mean percentage of words which reflect the given language in each newspaper article; these means are not weighted by the number of words in each article; * $p<0.1$; $* * \mathrm{p}<0.05 ; * * * \mathrm{p}<0.001$. 
government has proven disastrous for our most economically and socially challenged. A conservative agenda focused on limited free markets, competitive tax rates, schools demanding superior performance from both teachers and students, and robust private support for families in need might not be more effective. But, given the lifelong hardships many of these folks may endure, perhaps it is time that we try a different approach here. (Reed, 2013)

In Seattle (plurality), a letter to the editor also provided the most negative article:

Whether or not he wanted to do it, McGinn has deeply fractured the city. We now have neighborhoods at war with downtown, bicyclists at war with drivers and homeowners at war with apartment dwellers. Worse than that, we have a mayor at war with truth and common sense, and who has made absolutely no effort to bridge any gaps. (Pluckhahn, 2013)

A letter to the editor in Tulsa (plurality) indicated that the campaign had gone quite negative. The letter referred to a Facebook post by the wife of a candidate. The reader wrote:

The Tulsa mayoral campaign has reached a new low. Recently, Victoria Bartlett, wife of Mayor Dewey Bartlett, used her personal Facebook page to toss insults at her opponent's family. Posting a picture making snide comments about Bill Lobeck, Kathy Taylor's husband, and the classic car he was driving in the annual BooHaHa Parade is tasteless and immature. (Yeakey, 2013)

\section{Conclusions}

The theory of RCV civility suggests that in comparison with contests using plurality elections, those contests using RCV will be more positive than negative, and more likely to feature bargaining and accommodation. LIWC analysis of newspaper content provides the strongest evidence for the idea that RCV campaigns are more civil, but not all the evidence presented here is quite as convincing. Tweets in RCV cities had fewer positive words than plurality cities and more negative words than plurality cities. RCV tweet words were also more inclusive and more exclusive; more tentative and more certain. On the other hand, the qualitative evidence from tweets seems to indicate that some candidates are reaching out to each other, as differing ethnic groups do in case studies of RCV countries (Reilly, 2002). Examples of newspaper content presented simply show that there is positive and negative in articles and campaigns, and do not herein support the theory or not. The mixed results suggest that scholars must do more research in this area.

This is the first published study to examine campaign content for evidence of civility themes in local elections featuring RCV compared to plurality elections. Even though the results of the study are mixed, they do complement the findings of Donovan and colleagues (2016). Automated analysis of the newspaper articles in the three RCV cities and seven plurality cities shows more positive and less negative content. In RCV communities, candidate tweets do show them campaigning for more than simply a first-place vote, which is consistent with the findings of Robb (2011). Scholars should expand on this work as more cities and localities use RCV-it would be ideal to randomly select cities, rather than the intentional matching used herein.

As noted, coding newspaper content for positivity and negativity is well-established. Using tweets for this purpose below the federal level is not-most studies of Twitter today focus on presidential or congressional candidate tweets. Donald Trump's use of Twitter is legendary (e.g., Bratslavsky et al., 2020). A limitation of the Twitter portion of this study was that not all candidates in small cities-sometimes none-have and use Twitter. It is unclear how many local candidates nationwide use Twitter (perhaps an avenue for future research). It is not clear that many individuals beyond elites use Twitter, even in 2021. Comparing recent Twitter use to 2013 indicates that growth is rather slow. A 2019 Pew Research Center study indicates that 22 percent of Americans use Twitter, compared to 2013 when 18 percent used Twitter (Duggan \& Smith, 2013; Wojcik \& Hughes, 2019). Wojcik and Hughes find that Twitter users "are younger, more likely to identify as Democrats, more highly educated and have higher incomes than U.S. adults overall" (Wojcik \& Hughes, 2019). Their study shows that the top 10 percent of users create 80 percent of the content, which is not unlike what the present analysis found. This is a potential limitation of the study, but also an opportunity for future research: How do local candidates compare to recent national discourse?

Another limitation of the study is the measurement of civility using automated text coding, even though scholars' use of big data analysis methods is cutting-edge. The qualitative analysis of the tweets provides evidence that the candidates are less likely to engage each other via tweets in plurality cities, but the quantitative analysis is not as clear. Even though LIWC has been carefully validated by scholars, coding words may have limitations because some words are coded as positive, when those same words might be seen as negative in the community. Computer programs that analyze word use typically do not catch sarcasm. On the other hand, the program allows the researcher to process and analyze a large amount of text in a reliable (in the sense of measuring the same thing every time, repeatable) way.

The purpose of this article was a broad test using text analysis to test the theory of RCV civility. However, this research suggests a number of paths for future research. First, more detailed coding of tweets might include cases where one candidate mentions the other as a measure of civility. Another future research avenue 
is the consideration of what happens after the election. Do we find that local meetings in RCV cities are more civil than those in plurality cities? This area of research is exciting and will continue to grow.

\section{Acknowledgments}

The author would like to thank Dr. Caroline Tolbert and the very helpful reviewers. Thank you also to Dr. John Szmer for his advice.

\section{Conflict of Interests}

The author declares no conflict of interests.

\section{Supplementary Material}

Supplementary material for this article is available online in the format provided by the author (unedited).

\section{References}

American Psychological Association. (n.d.-a). Anger. American Psychological Association. Retrieved from http://apa.org/topics/anger/index.aspx

American Psychological Association. (n.d.-b). Anxiety. American Psychological Association. Retrieved from http://apa.org/topics/anxiety/index.aspx

Bratslavsky, L., Carpenter, N., \& Zompetti, J. (2020). Twitter, incivility, and presidential communication: Theoretical incursion into spectacle and power. Cultural Studies, 34(4), 593-624. https://doi.org/10.1080/ 09502386.2019 .1656760

Brodeur, N. (2013, September 3). Mayor's arts awards honor raft of local luminaries. Seattle Times, p. B1.

Donovan, T., Tolbert, C., \& Gracey, K. (2019). Selfreported understanding of ranked choice voting. Social Science Quarterly, 100(5), 1768-1777. http:// doi.org/10.1111/ssqu.12651

Donovan, T., Tolbert, C., \& Gracey, K. (2016). Campaign civility under preferential and plurality voting. Electoral Studies, 42, 157-163. https://doi.org/10.1016/ j.electstud.2016.02.009

Duggan, M., \& Smith, A. (2013, December 30). Social media update. Pew Research Center. Retrieved from https://www.pewresearch.org/internet/2013/ 12/30/social-media-update-2013

Eulau, H. (1973). Technology and the fear of the politics of civility. Journal of Politics, 35(2), 367-385. https:// doi.org/10.2307/2129074

Farrell, D. M., \& McAllister, I. (2006). Voter satisfaction and electoral systems: Does preferential voting in candidate-centred systems make a difference? European Journal of Political Research, 45(5), 712-749. https://doi.org/10.1111/j.1475-6765.2006.00633.x

Herbst, S. (2010). Rude democracy: Civility and incivility in American politics. Philadelphia, PA: Temple University Press.
Horowitz, D. L. (1991). Making moderation pay: The comparative politics of ethnic conflict management. In J. V. Montville (Ed.), Conflict and peacemaking in multiethnic societies (pp. 451-476). Lanham, MD: Lexington Books.

John, S., \& Douglas, A. (2017). Candidate civility and voter engagement in seven cities with ranked choice voting. National Civic Review, 106(1), 25-29. http:// doi.org/10.1002/ncr.21307

Kotsopoulos, N. (2013, September 25). Same mayoral hopefuls stay from May to November 5-Consistency for Petty, Lukes, Coleman, Feegbeh. Worcester Telegram and Gazette.

Magleby, D. B., Monson, Q. J., \& Patterson, K. D. (Eds.). (2007). Dancing without partners: How candidates, parties, and interest groups interact in the presidential campaign. Lanham, MD: Rowman \& Littlefield.

Nielson, L. (2017). Ranked choice voting and attitudes toward democracy in the United States: Results from a survey experiment. Politics \& Policy, 45(4), 535-570. http://doi.org/10.1111/polp.12212

Pang, B., \& Lee, L. (2008). Opinion mining and sentiment analysis. Foundations and Trends in Information Retrieval, 2(1/2), 1-135. http://dx.doi.org/ 10.1561/1500000011

Pennebaker, J. W., Chung, C. K., Ireland, M., Gonzales, A., \& Booth, R. J. (2007). The development and psychometric properties of LIWC2007. Austin, TX: LIWC. Retrieved from https://www.liwc.net/ LIWC2007LanguageManual.pdf

Pennebaker, J. W., \& Lay, T. C. (2002). Language use and personality during crises: Analyses of mayor Rudolph Giuliani's press conferences. Journal of Research in Personality, 36(3), 271-282. https://doi.org/ 10.1006/jrpe.2002.2349

Pennebaker, J. W., Mehl, M. R., \& Niederhoffer, K. G. (2003). Psychological aspects of natural language use: Our words, our selves. Annual Review of Psychology, 54, 547-577. http://doi.org/10.1146/annurev.psych. 54.101601.145041

Peterson, D. M., \& Djupe, P. A. (2005). When primary campaigns go negative: The determinants of campaign negativity. Political Research Quarterly, 58(1), 45-54. https://doi.org/10.101177/ 106591290505800104

Pluckhahn, C. (2013, July 29). Political war zone. Seattle Times.

Reed, M. H. (2013, October 28). Minneapolis may need a philosophical shift. Star Tribune, p. 8A.

Reilly, B. (2002). Electoral systems for divided societies. Journal of Democracy, 13(2), 156-170. https://doi. org/10.1353/jod.2002.0029

Ridout, T. N., \& Franz, M. (2008). Evaluating measures of campaign tone. Political Communication, 25(2), 158-179. https://doi.org/10.1080/10584600 801985409

Robb, D. M. (2011). The effect of instant runoff voting on democracy (Unpublished Doctoral dissertation). Uni- 
versity of California, Irvine, USA.

Sigelman, L., \& Kugler, M. (2003). Why is research on the effects of negative campaigning so inconclusive? Understanding citizens' perceptions of negativity. Journal of Politics, 65(1), 142-160. https://doi. org/10.1111/1468-2508.t01-1-00007

West, D. M. (2014). Air wars: Television advertising and social media in election campaigns (6th ed.). Washington, DC: Congressional Quarterly Press.

Wojcik, S., \& Hughes, A. (2019, April 24). Sizing up Twitter users. Pew Research Center. Retrieved from https://www.pewresearch.org/internet/2019/ 04/24/sizing-up-twitter-users

Yeakey, B. (2013, November 6). New low. Tulsa World.

Young, L., \& Soroka, S. (2012). Affective news: The automated coding of sentiment in political texts. Political Communication, 29(2), 205-231. https://doi.org/ 10.1080/10584609.2012.671234

Youth, diversity win in Minneapolis vote-DFL machine that long-dominated city politics took a hit. (2013, November 7). Star Tribune, p. 10 A.

\section{About the Author}

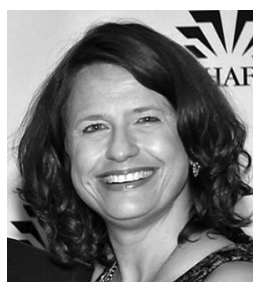

Martha Kropf (PhD) is Professor of Political Science and Public Policy at the University of North Carolina at Charlotte Department of Political Science and Public Administration. She is author of Institutions and the Right to Vote in America (2016; Macmillan/Palgrave) as well as co-author of the forthcoming A Republic If You Can Afford It: How Much Does It Cost to Administer an Election? She has published election administration research in Public Opinion Quarterly and the American Journal of Political Science. 